\title{
Acquisition, Extinction, and Reacquisition of a Cerebellar Cortical Memory Trace
}

\author{
Dan-Anders Jirenhed, Fredrik Bengtsson, and Germund Hesslow \\ Department of Experimental Medical Science, Lund University, 22184 Lund, Sweden
}

\begin{abstract}
Associative learning in the cerebellum underlies motor memories and probably also cognitive associations. Pavlovian eyeblink conditioning, a widely used experimental model of such learning, depends on the cerebellum, but the memory locus within the cerebellum as well as the underlying mechanisms have remained controversial. To date, crucial information on how cerebellar Purkinje cells change their activity during learning has been ambiguous and contradictory, and there is no information at all about how they behave during extinction and reacquisition. We have now tracked the activity of single Purkinje cells with microelectrodes for up to $16 \mathrm{~h}$ in decerebrate ferrets during learning, extinction, and relearning. We demonstrate that paired peripheral forelimb and periocular stimulation, as well as paired direct stimulation of cerebellar afferent pathways (mossy and climbing fibers) consistently causes a gradual acquisition of an inhibitory response in Purkinje cell simple spike firing. This conditioned cell response has several properties that matches known features of the behavioral conditioned response. The response latency varies with the interstimulus interval, and the response maximum is adaptively timed to precede the unconditioned stimulus. Across training trials, it matches behavioral extinction to unpaired stimulation and also the substantial savings that occur when paired stimulation is reinstated. These data suggest that many of the basic behavioral phenomena in eyeblink conditioning can be explained at the level of the single Purkinje cell.
\end{abstract}

Key words: cerebellum; Purkinje cell; classical conditioning; eyeblink; climbing fiber; mossy fiber

\section{Introduction}

It is now well known that a basic form of associative memory depends on the cerebellum. In pavlovian or "classical" eyeblink conditioning, a neutral "conditioned" stimulus (CS) is followed by a blink-eliciting, unconditioned, stimulus (US). With repeated CS-US presentations, the CS gradually acquires the ability to elicit a conditioned blink response $(\mathrm{CR})$ (see Fig. $1 \mathrm{~B}$ ) on its own (Kehoe and Macrae, 2002). A large body of work, beginning with McCormick and Thompson (1984), has shown that such learning is abolished or seriously impaired if certain parts of the cerebellum are lesioned or inactivated (Hesslow and Yeo, 2002; Christian and Thompson, 2003). Because the cerebellum has been implicated in both cognitive and emotional functions (Schmahmann, 1997), the neural processes underlying eyeblink conditioning are probably not restricted to motor functions and may be an example of a quite general mechanism of associative memory.

Although it is clear that the critical processes are located in the cerebellum, the exact nature and localization of the neural memory trace has remained elusive. According to some models, the memory trace is located in the cerebellar nuclei, possibly aided by a timing signal from the cerebellar cortex (Lavond, 2002; Chris-

Received Sept. 26, 2006; revised Jan. 29, 2007; accepted Jan. 30, 2007.

This work was supported by Swedish Research Council Grant 09899 and the Knut and Alice Wallenberg Foundation.

Correspondence should be addressed to Dan-Anders Jirenhed, Department of Experimental Medical Science, Lund University, Biomedical Center F10, 22184 Lund, Sweden. E-mail: dan-anders.jirenhed@med.lu.se. DOI:10.1523/JNEUROSCI.4202-06.2007

Copyright $\odot 2007$ Society for Neuroscience $\quad$ 0270-6474/07/272493-10\$15.00/0 tian and Thompson, 2005; Thompson, 2005). The cerebellar cortical conditioning model (Hesslow and Yeo, 2002), as well as a model that combines cortical and nuclear plasticity (Mauk and Donegan, 1997; Medina et al., 2001), which were inspired by previous theoretical (Marr, 1969; Albus, 1971) and empirical (Gilbert and Thach, 1977; Ito, 2001) work on cerebellar plasticity and on cerebellar anatomy (Yeo et al., 1985), propose that the spontaneously active Purkinje cells learn to reduce their firing below the spontaneous background level in response to the CS. Because Purkinje cells are inhibitory, this would cause a disinhibition of the nuclear neurons and an increased output in the downstream motor pathways.

It is generally accepted that the CS reaches the cerebellum via the mossy fiber afferents and that the US is transmitted via the climbing fibers (Hesslow and Yeo, 2002; Christian and Thompson, 2003). Paired presentations of a direct mossy fiber CS and a direct climbing fiber US should therefore result in a change in the Purkinje cell response to the mossy fiber CS similar to that caused by paired peripheral CS-US presentations. Conversely, unpaired mossy and climbing fiber stimulation would be expected to cause extinction of the Purkinje cell response, similar to behavioral extinction observed to unpaired CS-US presentations. Finally, reinstated pairing of CS-US presentations after extinction causes rapid reacquisition of conditioned behavioral responses and should be accompanied by a rapid return of the Purkinje cell response.

To test these predictions, we made extracellular recordings from single Purkinje cells in vivo in a decerebrate ferret preparation. Rather than sampling from a large number of loosely defined cells, our aim was to obtain long-term recordings from 
Table 1. Purkinje cell records using $300 \mathrm{~ms}$ CS-US interval

\begin{tabular}{|c|c|c|c|c|c|}
\hline Animal & Cell & Duration & Acquisition (11 records/10 cells/10 animals) & Extinction (9 records/9 cells/9 animals) & Reacquisition (5 records/4 cells/4 animals) \\
\hline 1 & 1 & $5 \mathrm{~h}$ & Forelimb + inferior olive, 240 trials & & \\
\hline 2 & 2 & $7 \mathrm{~h}$ & Forelimb + inferior olive, 44 trials & & \\
\hline 3 & 3 & $13 \mathrm{~h}$ & Forelimb + inferior olive, 200 trials & Forelimb, 940 trials & \\
\hline 4 & 4 & $8 \mathrm{~h}$ & Forelimb + inferior olive, 640 trials & Forelimb, 680 trials & \\
\hline 5 & 5 & $16 \mathrm{~h}$ & Mossy fibers + inferior olive, 900 trials & Mossy fibers alone, 480 trials & Mossy fibers + inferior olive, 240 trials \\
\hline 5 & 5 & $16 \mathrm{~h}$ & Forelimb + inferior olive, 620 trials & & \\
\hline 6 & 6 & $4 \mathrm{~h}$ & Mossy fibers + inferior olive, 620 trials & & \\
\hline 7 & 7 & $5 \mathrm{~h}$ & Mossy fibers + inferior olive, 400 trials & Mossy fibers + inferior olive unpaired, 520 trials & \\
\hline 8 & 8 & $3 \mathrm{~h}$ & Mossy fibers + inferior olive, 580 trials & & \\
\hline 8 & 9 & $3 \mathrm{~h}$ & & & Mossy fibers + inferior olive, 40 trials \\
\hline 9 & 10 & $5 \mathrm{~h}$ & Mossy fibers + climbing fibers, 620 trials & Mossy fibers + climbing fibers unpaired, 440 trials & \\
\hline 10 & 11 & $4 \mathrm{~h}$ & & Mossy fibers + climbing fibers unpaired, 680 trials & \\
\hline 11 & 12 & $5 \mathrm{~h}$ & & Mossy fibers + climbing fibers unpaired, 580 trials & Mossy fibers + climbing fibers, 170 trials \\
\hline 12 & 13 & $7 \mathrm{~h}$ & Mossy fibers + eyes, 740 trials & Mossy fibers + eyes unpaired, 440 trials & \\
\hline 13 & 14 & $7 \mathrm{~h}$ & & Mossy fibers + eyes unpaired, 680 trials & Mossy fibers + eyes, 100 trials \\
\hline 13 & 14 & $7 \mathrm{~h}$ & & & Mossy fibers + climbing fibers, 200 trials \\
\hline
\end{tabular}

Summary of Purkinje cell data obtained during CS-US training (acquisition, extinction, or reacquisition) using a $300 \mathrm{~ms}$ interstimulus interval. In all, single-unit activity from 14 Purkinje cells was recorded in 13 animals during acquisition, extinction, and reacquisition.

Purkinje cells with well defined input characteristics in the $\mathrm{C} 3$ zone blink-controlling area (see Fig. 1C). Purkinje cells in this area receive both mossy fiber and short-latency (10-12 ms) climbing fiber input on periocular stimulation (see Fig. 2 A). Recordings were made during paired and unpaired CS and US presentations, using both peripheral and central stimulation.

\section{Materials and Methods}

Subjects, surgery, and anesthesia. Subjects were 19 ferrets (1-2 kg), initially anesthetized in a mixture of $\mathrm{O}_{2}$ and air with 1.5-2\% isoflurane (Baxter Medical, Kista, Sweden), which was then replaced by propofol (10 mg/ml Diprivan; AstraZeneca, Södertälje, Sweden) intravenously. When deep anesthesia had been achieved, a tracheotomy was performed and the gas was then channeled directly into a tracheal tube. The endexpiratory $\mathrm{CO}_{2}$ concentration, arterial blood pressure, and rectal temperature were monitored continuously and kept within physiological limits throughout the experiment. During the whole experiment, infusion was given intravenously $[50 \mathrm{mg} / \mathrm{ml}$ glucose and isotonic acetate Ringer's solution (proportion 1:1) with $0.004 \mathrm{mg} / \mathrm{ml}$ albumin fraction V (from bovine serum) (Sigma-Aldrich, St. Louis, MO); 2 $\left.\mathrm{mg} \cdot \mathrm{kg}^{-1} \cdot \mathrm{h}^{-1}\right]$. The animal's head was fixed in a stereotaxic frame. The skull was then opened on the left side, and the caudal half of the left cerebral hemisphere, together with a substantial part of the thalamus on the left side, were removed by aspiration. The aspiration exposed the cerebellum and the superior and inferior colliculi. The animals were decerebrated by sectioning the brainstem with a blunt spatula $1-2 \mathrm{~mm}$ rostral to the superior colliculus. The completeness of the decerebration was always confirmed by postmortem examinations. After decerebration, anesthesia was discontinued. With the cerebellum and colliculi exposed, a pool was constructed of cotton reinforced agar and filled with warm high-density perfluoro carbon liquid (FC-40 Fluorinert; 3M, Zwijndrecht, Belgium). To ensure mechanical stability in the tissue, the animals were curarized, artificially ventilated, and were kept hanging by the spine, with the head fixed in the stereotaxic frame. A bilateral pneumothorax was also performed to minimize chest movements and movements caused by changes in venous blood pressure. The dura covering the cerebellum was removed, and the cerebellar surface was covered with agarose gel $(10 \mathrm{mg} / \mathrm{ml})$ to provide recording stability and prevent edema near the site of recording. This study has been reviewed and approved by the local Swedish Ethical Committee.

Training protocol. Stimulation of cerebellar afferents during conditioning to a $300 \mathrm{~ms}$ CS-US interval involved 13 animals (Table 1) and followed a protocol analogous to eyeblink conditioning in previous studies in our laboratory (Hesslow and Ivarsson, 1994; Hesslow et al., 1999), i.e., delay conditioning with nonoverlapping CS and US presentations. As illustrated in Figure $1 \mathrm{~A}$, the CS was a $300 \mathrm{~ms}, 50 \mathrm{~Hz}$ stimulus train applied to the ipsilateral forelimb skin (1.5-2.0 mA, $0.5 \mathrm{~ms}$ pulse duration) or to mossy fibers in the middle cerebellar peduncle $(90-100 \mu \mathrm{A}$, $0.1 \mathrm{~ms}$ pulse duration). The US consisted of two $10 \mathrm{~ms}$ stimulus trains delivered with a $20 \mathrm{~ms}$ interval, each train consisting of five square pulses $(0.1 \mathrm{~ms}$ pulse duration) at $500 \mathrm{~Hz}$. The stimulation was delivered to the inferior olive $(70-320 \mu \mathrm{A})$, to the climbing fibers in the inferior cerebellar peduncle (15-90 $\mu \mathrm{A})$, or to the periocular skin $(3 \mathrm{~mA})$. The stimulus parameters used for direct climbing fiber stimulation were designed to mimic the strongest climbing fiber response that is likely to occur under natural conditions. They were justified by two observations: (1) that a peripheral stimulus often elicits two complex spikes in the Purkinje cell separated by 10-20 ms (Ekerot et al., 1987), and (2) by the fact that the olive responds to a peripheral stimulus with a burst of two to six spikes (Simpson et al., 1996). During paired stimulation, the US was presented $300 \mathrm{~ms}$ after CS onset. The intertrial interval was $15 \mathrm{~s}$. Extinction training consisted of either CS alone presentations or presentations of both CS and US but with pseudorandom intervals between them.

Conditioning to a $200 \mathrm{~ms}$ CS-US interval involved six animals and was done as described above, with one difference apart from the shorter interstimulus interval: the CS consisted of a longer, $600 \mathrm{~ms}(50 \mathrm{~Hz})$, stimulus train that overlapped and extended $400 \mathrm{~ms}$ beyond the US presentation. In all of these cases, the US consisted of climbing fiber stimulation in the inferior cerebellar peduncle as described above.

Cerebellar afferent stimulation sites. The contralateral dorsal accessory (inferior) olive was stimulated with an electrode lowered into the brainstem just caudal to the cerebellar vermis, at an angle of $45^{\circ}, 1-1.25 \mathrm{~mm}$ lateral to the midline and at a depth of $4.0-5.5 \mathrm{~mm}$. While tracking for the optimal stimulation site, single pulses $(1 \mathrm{~mA})$ were applied and climbing fiber field potentials were recorded in a blink controlling area of the C3 zone of hemispheral lobule VI, identified by previously established criteria (Hesslow, 1994a,b). The climbing fiber response latency was $\sim 4.0 \mathrm{~ms}$ (see Fig. $2 B$ ).

The climbing fibers in the ipsilateral inferior cerebellar peduncle were stimulated in the brainstem by lowering the electrode $4.0-5.0 \mathrm{~mm}$ below the posterior cerebellar surface, at an angle of $45^{\circ}, 4 \mathrm{~mm}$ lateral to the midline and $4 \mathrm{~mm}$ rostral to the caudal border of the cerebellar vermis. While tracking for the optimal stimulation site, single electrical pulses $(100 \mu \mathrm{A})$ were applied while recording from the cerebellar surface. The elicited climbing fiber field potentials had a response latency of $\sim 2.0 \mathrm{~ms}$ (see Fig. 2C).

The mossy fibers in the ipsilateral middle cerebellar peduncle were stimulated with an electrode lowered into the brainstem through the inferior colliculus at an angle of $80^{\circ}, 1 \mathrm{~mm}$ medial to the lateral border of the inferior colliculus and at a depth of 4.0-5.0 mm. While tracking for the optimal stimulation site, single electrical pulses $(100 \mu \mathrm{A})$ were ap- 


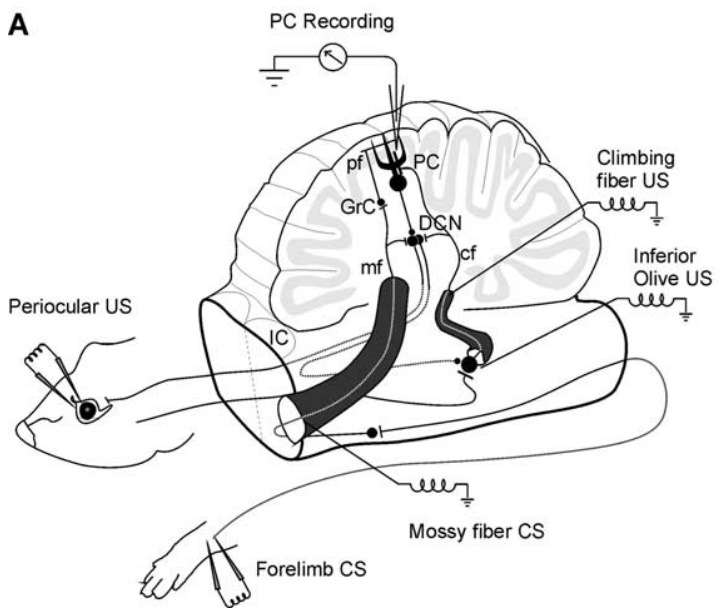

B

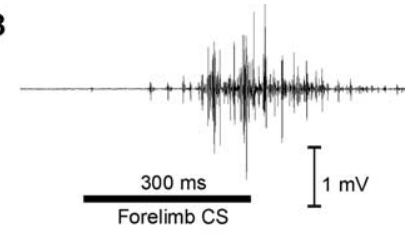

C

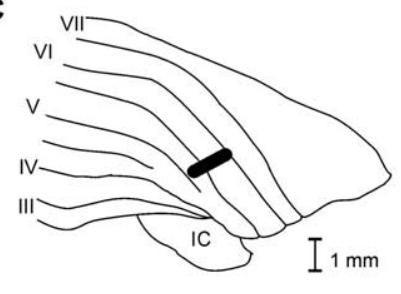

no spikes of comparable amplitude present at any time, and (3) there were no sudden changes in spike amplitude. The position of the recording electrode occasionally had to be adjusted, but this could usually be done without violating these criteria.

Several of the experimental procedures described above were intended to reduce tissue movement and optimize the recording stability, such as having the animal hanging by the spine, fixating the head in the stereotaxic frame, bilateral pneumothorax, curarization, and covering the cerebellar surface with agarose gel. This enabled us to record from the same cell for many hours, occasionally $10-15 \mathrm{~h}$ or more.

Data analysis and statistics. The recorded electrical signals were passed unfiltered through an amplifier and a Micro1401 data acquisition analog-to-digital converter unit (Cambridge Electronics Design, Cambridge, UK). The sampling rate was $40 \mathrm{kHz}$. Data analysis was performed using the Spike2 version 5 software (Cambridge Electronics Design).

The onset latency for Purkinje cell CRs was determined using the following procedure. Spike frequency during the CS period was

plied while recording from the cerebellar surface. The elicited mossy fiber field potentials had a response latency of $\sim 1.0 \mathrm{~ms}$ (see Fig. $2 D$ ).

Direct stimulation of cerebellar afferents was in all cases done with tungsten electrodes (diameter, $30 \mu \mathrm{m}$; deinsulated tip, $50 \mu \mathrm{m}$ ). The effectiveness of all stimulation sites and stimulus intensities were verified again and adjusted if necessary, when recording the activity of single Purkinje cells. Examples of Purkinje cell responses to direct stimulation are presented in Figure 2, $F$ (olivary stimulation), $G$ (climbing fiber stimulation), and $H$ (mossy fiber stimulation).

Purkinje cell recordings. Extracellular single-unit recordings of Purkinje cells, identified by the presence of complex spikes, were performed using quartz glass-coated platinum-tungsten fiber microelectrodes with pulled and ground tips; 30-40 $\mu \mathrm{m}$ metal core diameter (Thomas Recording, Giessen, Germany). All Purkinje cells were located in a blinkcontrolling area of the $\mathrm{C} 3$ zone of the ipsilateral hemispheral lobule VI. Additionally, the following criteria were postulated for inclusion of Purkinje cell in the dataset: (1) verified climbing fiber input from US, (2) verified mossy fiber input from CS, and (3) sufficient recording stability to obtain a documented change in the response to CS during training. Climbing fiber input from the US was readily verified by the reliable occurrence of complex spikes. Mossy fiber input from the CS could in most cases be verified by reliable increases in simple spike activity on presentation of a $300 \mathrm{~ms}$ stimulus train, but, in some cases, responses were too weak to be observable in a single trial and averaging over several trials were necessary to confirm the presence of a response.

The following recording strategy was used for obtaining single-cell records during conditioning: (1) Find Purkinje cell (identified by presence of spontaneous complex spikes) in naive animal. (2) Verify identity as eyeblink-controlling cell in C3 by monitoring responses to periorbital stimulation. (3) Verify afferent mossy and climbing fiber inputs from the CS and US to be used. (4) Establish effective stimulation thresholds for CS and US. (5) Start paired CS-US presentations and record during acquisition phase. (a) If recording is sufficiently long and stable to observe a clear learning effect, proceed to step 6. (b) If cell is lost during training, continue with paired CS-US presentations, locate another cell, and go back to step 1. (6) If an identified Purkinje cell is found that reliably exhibits characteristic CRs and responds with complex spikes to US input, proceed with extinction training (unpaired CS-US or CSalone presentations). (a) If recording is sufficiently long and stable to observe a clear learning effect, proceed to reacquisition training (step 5) with same cell. (b) If cell is lost during training, continue with extinction training, locate another cell, and go back to step 1.

A record was judged to be from the same Purkinje cell only if (1) the cell was observed continuously throughout the recording, (2) there were quantified in $10 \mathrm{~ms}$ bins over 40 trials and normalized relative to the average background activity in the preceding $600 \mathrm{~ms}$. The time point (bin) during the CS period in which spike activity decreased below background activity and remained there for $>50 \mathrm{~ms}$ (five consecutive bins) was considered to be the onset of the CR. The latency to maximum response was measured as the time point (bin) with the lowest activity after onset. In cases of identical activity for two or more consecutive time points, e.g., during a complete pause $(0 \mathrm{~Hz})$ consistent over 40 trials, the last time point of this period was chosen as the latency to maximum response.

The average activity plots in Figures $3 C, 5 C$, and $6 C$ were constructed using the image plot function in Matlab version 7 (MathWorks, Natick, MA). Each plot consists of squares, in which each square represents the spike activity of the Purkinje cell population during a $10 \mathrm{~ms}$ time window. Spike activity was first calculated for each individual cell in $10 \mathrm{~ms}$ bins by averaging spike frequency over 20 trials and then normalizing it relative to the average background activity in the preceding $600 \mathrm{~ms}$. All of the individual cell activity values were then averaged over the whole population, thus yielding an average response profile with a resolution of $10 \mathrm{~ms} \times 20$ trials. The activity during reacquisition was analyzed in averages of 10 trials instead of 20 , because the change in response profile proved very rapid.

\section{Results}

In searching for Purkinje cells, we first located the blinkcontrolling area (Fig. 1C) of the C3 zone of the cerebellar cortex, identified with previously established criteria in decerebrate cats and ferrets (Ivarsson and Hesslow, 1993; Hesslow, 1994a,b). Purkinje cells in this area receive both mossy fiber and short-latency (10-12 ms) climbing fiber input on periocular stimulation (Fig. $2 A)$. The climbing fiber pathway from the inferior olive to this area was then located by electrical stimulation (Fig. $2 B, C$ ). When using direct mossy fiber stimulation as the CS, we confirmed that this elicited mossy fiber field potentials in the recording area (Fig. 2D).

When a Purkinje cells was first encountered in an experiment, its periocular climbing fiber input was first verified (Fig. $2 E$ ), and then it was checked that stimulation of the inferior olive or the climbing fibers reliably elicited complex spikes and no simple spikes (Fig. $2 F, G$ ). It was also confirmed that direct mossy fiber stimulation did not elicit complex spikes (Fig. $2 H$ ). 
After these initial tests, we tried to hold the cell during paired CS-US presentations (acquisition training), until a robust change had been established. The CS was a $300 \mathrm{~ms}, 50 \mathrm{~Hz}$ train of electrical stimuli applied to the forelimb skin or to mossy fibers in the middle cerebellar peduncle. The US was electrical stimulation of the periocular skin, the inferior olive, or the climbing fibers in the inferior cerebellar peduncle (Fig. 1 $A$ ).

If a change in the Purkinje cell response to the CS was obtained, the cell was followed during CS alone or unpaired CS-US presentations (extinction training) until the change had been reversed. At this stage, paired stimulation was applied again (reacquisition training) until the response had recovered. If the cell was lost before extinction training, we tried to find another cell that responded in the same way to the CS and US to follow it through unpaired stimulation (for more details, see Materials and Methods).

The resulting sample of Purkinje cell recordings from 14 cells during training with the 300 ms CS-US interval is summarized in Table 1. Acquisition data were obtained from 10 cells. In one of these (cell 5 ), acquisition was followed twice, first to a mossy fiber CS and then to a forelimb CS. In six of these cells, it was also possible to follow extinction. Extinction was also followed in an additional three Purkinje cells, in which recording was begun after acquisition. Reacquisition was studied in four cells. One of these had been followed through both acquisition and extinction; two had been followed during extinction and one cell was encountered after the animal had undergone both acquisition and extinction training. One of the four cells (Table 1, cell 14) was followed during two reacquisition sessions, first using the periorbital US and later using a climbing fiber US.

In addition to the recordings from the 14 cells described above and summarized in Table 1, another set of nine cells in six animals were observed during acquisition using a $200 \mathrm{~ms}$ CS-US interval (for details, see Materials and Methods). In all, data from 23 Purkinje cells are thus included here. The purpose of using this second group was to investigate effects on timing of Purkinje cell responses acquired to a shorter CS-US interval. The results from comparing responses acquired to the longer $300 \mathrm{~ms}$ versus the shorter $200 \mathrm{~ms}$ intervals are presented below. The main focus of the remaining analysis is, however, on the 14 cells included in Table 1.

\section{Acquisition}

Eleven recordings were made from 10 Purkinje cells in 10 animals during acquisition to the $300 \mathrm{~ms}$ CS-US interval (for details, see Table 1). Recordings during acquisition covered 200 trials (50 $\mathrm{min}$ ) in the shortest case and 900 trials ( $3 \mathrm{~h} 45 \mathrm{~min}$ ) in the longest case. Eight of the 11 recordings started from a naive state, i.e., the animals had not been exposed to paired CS-US presentations before recording. However, in one case (cell 5), the cell had first been trained with a mossy fiber CS and was then trained again using forelimb stimulation as the CS. It had thus been exposed to a CS, but a different one, before the second training period, and the second CS did not elicit the response that had been acquired to the first CS. In the three non-naive cases, the first encountered Purkinje cell was lost early, and training was continued when another cell was found. These cells were not strictly naive, when recording was begun, but because the number of lost trials was small and no learning effects were evident from the cell responses early in training, we included them in the material.

In all 10 Purkinje cells followed during learning, paired CS and US presentations caused cells to gradually acquire a long-latency inhibitory response to the CS, here called a "Purkinje cell CR." A typical example is illustrated by individual records before and after training and with a raster plot (Fig. $3 A, B$ ). A composite raster plot based on the 11 cell records obtained during conditioning to the $300 \mathrm{~ms}$ interval is shown in Figure 3C. The acquisition of these Purkinje cell CRs was remarkably uniform across all cells (Fig. 3D).

Note that what appears in Figure $3 C$ to be a change in the response to the US is actually a change in the response to the CS and US. We did not attempt to study responses to the US in the 
A
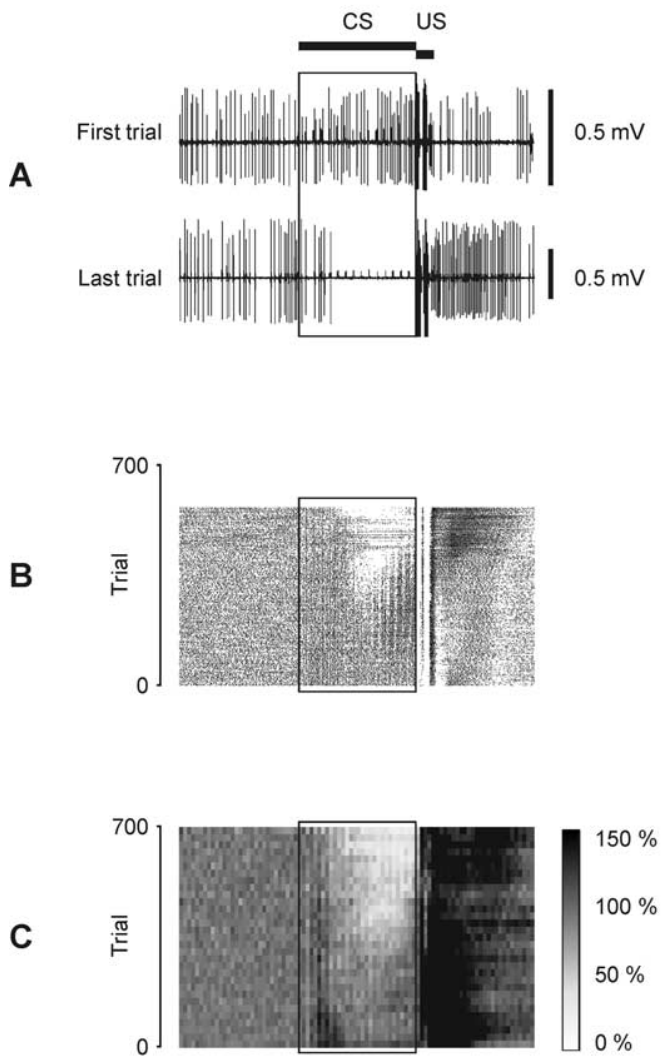
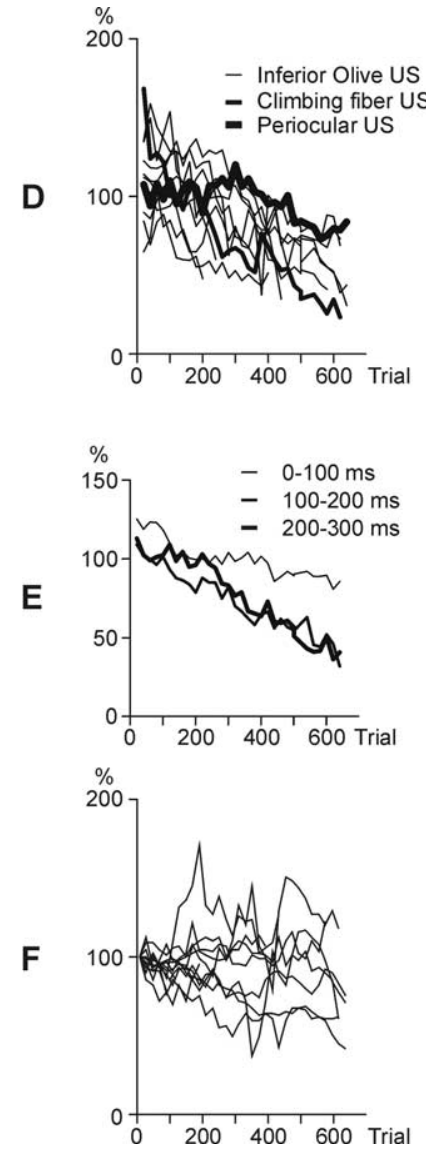

Figure 3. Acquisition of Purkinje cell CR. A, Two sample records from a Purkinje cell exposed to paired CS-US presentations (bars above graph), from trial 1 (top) and 640 trials later (bottom). The acquired Purkinje cell response had a latency of $\sim 60 \mathrm{~ms}$. $B$, Raster plot of the simple spike activity recorded from the same cell during 640 trials of paired CS-US presentations. The inhibitory response during the $C S$ period (framed) gradually developed as training progressed. $C$, Average raster plot based on 11 Purkinje cell records during acquisition. The plot is built up of squares, the shadings of which indicate average firing rate across all cells (for details, see Materials and Methods). The light area that gradually appears represents the Purkinje cell $C R$, i.e., an inhibitory response with a firing rate below background level (100\%). The darker areas indicate increased simple spike activity. $\mathbf{D}$, Simple spike activity in 11 individual Purkinje cell records shown as plots of firing frequency (percentage of background activity) during the whole $300 \mathrm{~ms}$ CS period. There is a consistent decrease in all cells regardless of whether periocular, olivary, or climbing fiber stimulation was used as US. In one cell, acquisition was observed twice: first using a mossy fiber CS and later using a forelimb CS (see Table 1).E, Temporal analysis of simple spike activity. The $300 \mathrm{~ms}$ CS period was divided into three $100 \mathrm{~ms}$ periods that are plotted individually. During acquisition, there was only a slight decrease in firing rate during the first $100 \mathrm{~ms}$ compared with the change observed in the rest of the $C S$ period. $\boldsymbol{F}$, Spontaneous simple spike activity during the $600 \mathrm{~ms}$ period before $C S$ presentation in 11 individual Purkinje cell records, shown as percentage of background activity when recording started.

present investigation. However, the change was not caused by changes in climbing fiber activation. To ensure stability of training conditions, it was repeatedly verified throughout the experiments that the US elicited complex spikes.

Reliable inhibitory responses to the CS were observed in all 23 Purkinje cells (from both interstimulus interval groups) after paired CS-US presentation, although some of the cells had not been followed during the whole acquisition phase.

Before training, Purkinje cells generally exhibited a weak excitatory response to the CS with an average simple spike frequency at $120 \%$ of background (Fig. 3C,D). During paired CS-US presentations, an inhibitory Purkinje cell CR gradually developed in response to the CS that decreased simple spike activity below background level. After 640 trials, cells on average responded with a $50 \%$ reduction of their firing over the whole 300 ms CS period (Fig. 3D). This is a conservative figure because it refers to the whole CS-US interval and the inhibitory response was not uniform throughout this interval (see below).
The early increase in simple spike firing that was elicited by the CS, i.e., the dark area in the CS period that can be seen in the first 100 trials of training in Figure $3 C$, tended to disappear during the training before the appearance of the Purkinje cell CR. However, this was not always the case, as is evident from the reacquisition example record in Figure $6 A$ (top record) and the raster plot in Figure $6 B$.

The background activity did not change in any systematic way during either paired or unpaired CS-US presentations. Some cells developed increased spontaneous simple spike activity, whereas others showed decreased activity, or repeated variations up and down (see Figs. $3 F, 5 F, 6 F)$.

\section{Time course of Purkinje cell CR}

To analyze the time course of the change in the Purkinje cell response, the CS-US interval was divided into three $100 \mathrm{~ms}$ intervals. As shown in Figure 3E, after 640 trials, the acquired inhibition during the first 100 ms was only $\sim 15 \%$ on average but reached $77 \%$ during the following 200 ms. Often the CS elicited a near 100\% inhibition, amounting to a complete pause in firing that lasted for 150-350 $\mathrm{ms}$ on individual trials (for examples, see Figs. $3 A$, bottom, and $5 A$, top). Inhibitory responses sampled from all 14 cells trained with the $300 \mathrm{~ms}$ CS-US interval and averaged over 40 trials had a mean \pm SD latency to onset of $59 \pm 24 \mathrm{~ms}$ and a latency to maximum response of $180 \pm 40 \mathrm{~ms}$ after CS onset. (For the criteria used in determining response latency, see Materials and Methods.)

The time course of fully developed Purkinje cell CRs after training with a 300 ms CS-US interval is illustrated as peristimulus time histograms in Figure $4 A-C$. All three kinds of unconditioned stimuli that were used induced very similar CRs. It is noteworthy that the response is not a gradual decrease in firing from the start of the CS. Instead, the cell either did not change at all or, in some cases, increased its firing during the first 50-100 ms, after which there was a rather abrupt fall in firing frequency down to almost complete silence. The apparent gradual decrease in activity seen in some of the histograms is mainly an effect of variations in response latency between trials (for single-trial examples, see records and raster plots in Figs. 3, 5, 6). On some individual trials, particularly when a $200 \mathrm{~ms}$ CS-US interval was used (see below), the cell fired only one or two simple spikes after the CS onset, so the onset latency was only a couple of milliseconds.

One of the most salient features of behavioral CRs is that they are adaptively timed, that is, they tend to occur just before the expected US onset (Kehoe and Macrae, 2002). The shorter the CS-US interval, the earlier the CR tends to occur. To find out whether this was also true of Purkinje cell CRs, we tested acquisition to a shorter $200 \mathrm{~ms}$ CS-US interval in another group of 
300 ms CS-US interval $300 \mathrm{~ms}$ CS A

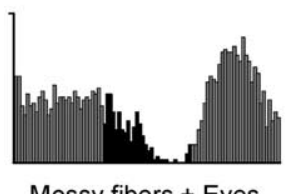

Mossy fibers + Eyes
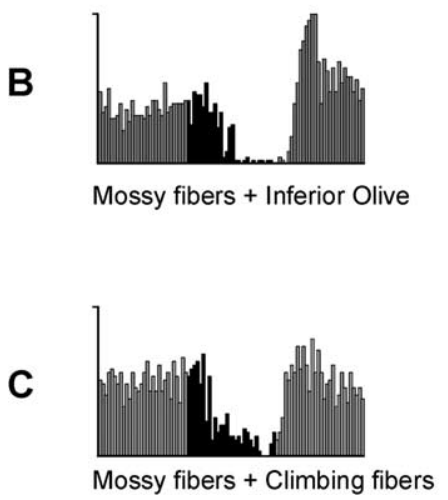

200 ms CS-US interval

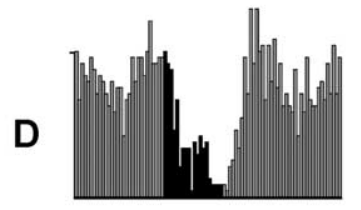

Mossy fibers + Climbing fibers $600 \mathrm{~ms} \mathrm{CS}$

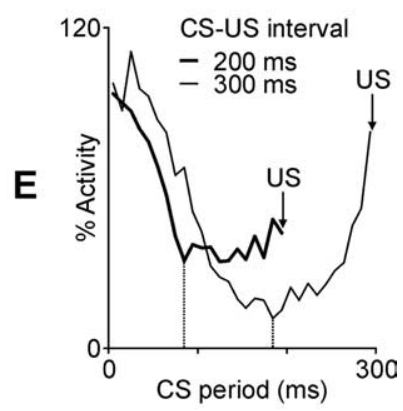

Figure 4. Timing of Purkinje cell responses. $\boldsymbol{A}-\boldsymbol{D}$, Peristimulus time histograms of conditioned Purkinje cell responses to $C S$-alone presentations (bars above graphs indicate $C S$ duration). The CS-US interval is the darkened part each histogram. Bin width is $10 \mathrm{~ms}$, and simple spike activity was averaged over 50 trials in $\boldsymbol{A}-\boldsymbol{C}$ and 20 trials in $\boldsymbol{D}$. The mark on the $y$-axis indicates $100 \mathrm{~Hz}$ simple spike frequency. $\boldsymbol{A}-\boldsymbol{C}$, Three examples of Purkinje cell responses to CS-alone stimulation in which CRs were acquired using a $300 \mathrm{~ms}$ mossy fiber CS and a $300 \mathrm{~ms}$ CS-US interval to different unconditioned stimuli (i.e., stimulation of the periorbital area, inferior olive, or climbing fibers). $\boldsymbol{D}$, This cell was trained with a longer $(600 \mathrm{~ms}) \mathrm{CS}$ and a shorter $(200 \mathrm{~ms})$ CS-US interval. $\boldsymbol{E}$, Average response profiles during CS period for Purkinje cells trained with 200 and $300 \mathrm{~ms}$ (S-US intervals, respectively, showing longer latency to both onset and maximum response (dotted lines) in the second group (for additional details, see Materials and Methods and Results).

nine cells in six animals. The resulting Purkinje cell CRs showed temporal characteristics similar to behavioral CRs, that is, the shorter CS-US interval resulted in a shorter latency to response onset and a shorter latency to maximum inhibitory response (Fig. $4 D$ ). Purkinje cell CRs sampled from all nine cells trained with the $200 \mathrm{~ms}$ CS-US interval and averaged over 20 trials had a mean onset latency of $26 \pm 26 \mathrm{~ms}$, which should be compared with $59 \pm 24 \mathrm{~ms}$ with the $300 \mathrm{~ms}$ CS-US interval. The latency to the maximum inhibitory response was $80 \pm 9 \mathrm{~ms}$ with the $200 \mathrm{~ms}$ interval, whereas it was $180 \pm 40 \mathrm{~ms}$ with the $300 \mathrm{~ms}$ interval. The difference in response onset latency between the long interval group and the short interval group proved statistically significant $(t=3.083 ; p<0.01)$, as did the difference in latency to maximum response $(t=7.264 ; p<0.001)$. A comparison of the average response profiles for the two groups (shown in Fig. $4 E$ ) clearly illustrated how Purkinje cells in the $200 \mathrm{~ms}$ group generally responded earlier than cells in the $300 \mathrm{~ms}$ group.

\section{Peripheral versus central stimulation as CS and US}

Periocular stimulation elicits climbing fiber responses in blinkcontrolling areas of the cerebellar cortex (Hesslow, 1994a), but it also activates mossy fiber afferents (as can be seen in Fig. $2 \mathrm{~A}$ ). To ensure that the climbing fiber input elicited by the US was critical for learning the Purkinje cell CR, we mainly used direct stimulation of the inferior olive as the US. This turned out to be at least as effective as the periocular stimulus. Although this strengthens the proposed role of the climbing fibers, it does not completely rule out alternative explanations. An olivary stimulus could inadvertently activate other pathways, for instance by antidromic activation of the trigeminal nucleus or by current spread to fibers of passage in the pons. As an additional control, we therefore also used direct stimulation of climbing fibers in the inferior cerebellar peduncle as a US. This also caused acquisition of a Purkinje cell CR. In one case (Table 1, cell 14), in which a Purkinje cell CR had been acquired with a periocular US and then extinguished, subsequent paired stimulation with a climbing fiber US caused reacquisition (see below). Thus, three different ways of activating climbing fibers all induced similar changes in the Purkinje cells.

The effects of paired CS-US presentations were the same whether the CS was a peripheral stimulus or direct mossy fiber stimulation, in agreement with previous demonstrations that the CS is transmitted via mossy fibers (Steinmetz et al., 1986; Hesslow et al., 1999).

\section{Extinction}

Recordings were made from nine cells in nine animals during extinction and covered 440 trials ( $1 \mathrm{~h} 50 \mathrm{~min}$ ) in the shortest case and 940 trials ( $3 \mathrm{~h} 55 \mathrm{~min}$ ) in the longest case (for details, see Table 1). Five of these cells had already been followed during acquisition before extinction training was initiated. Extinction training, consisting of either CS alone presentations (three cells) or of explicitly unpaired CS-US presentations (six cells), always had the reverse effect of acquisition, i.e., the inhibitory Purkinje cell CRs were gradually weakened and approached preacquisition levels (Fig. 5). No differences in extinction profiles were observed between the two extinction procedures.

During extinction training, reliable and strong inhibitory responses often persisted for 100 trials or more, before simple spike activity during the CS period gradually started to recover (Fig. $5 B, C$ ). Transient recovery of the Purkinje cell CRs (i.e., several consecutive trials in which pause responses returned) was observed after $\sim 500$ trials (in five of nine cells), a phenomenon that has also been observed in behavioral experiments (E. J. Kehoe, personal communication). However, after 640 trials of extinction, the average inhibitory response strength during the $300 \mathrm{~ms}$ CS period had decreased from 58 to $9 \%$ (Fig. 5C,D). As during acquisition, most of the change occurred during the later part of the CS period (Fig. 5E).

\section{Reacquisition}

It is well known from behavioral studies that, when paired CS-US presentations are resumed after extinction, there are substantial savings, that is, reacquisition of the CR is much more rapid than the initial acquisition (Kehoe and Macrae, 2002). This turned out to be true of Purkinje cell CRs as well. Five recordings were made from four cells in four animals during reacquisition (Table 1). Two of these cells had already been followed during extinction before reacquisition training was initiated. One cell was followed twice during reacquisition training: first with a periorbital US and later with a climbing fiber US. Recordings during reacquisition covered 40 trials $(10 \mathrm{~min}$ ) in the shortest case and 240 trials $(1 \mathrm{~h}$ ) in the longest case (for details, see Table 1). Paired CS-US presentations after extinction caused a very rapid return of the Purkinje cell CR, often within just a few trials (Fig. 6).

\section{Discussion}

\section{Paired CS and US activation induces learning of Purkinje cell CR}

Existing data on Purkinje cell activity during conditioning have been ambiguous and contradictory. We reported previously that 

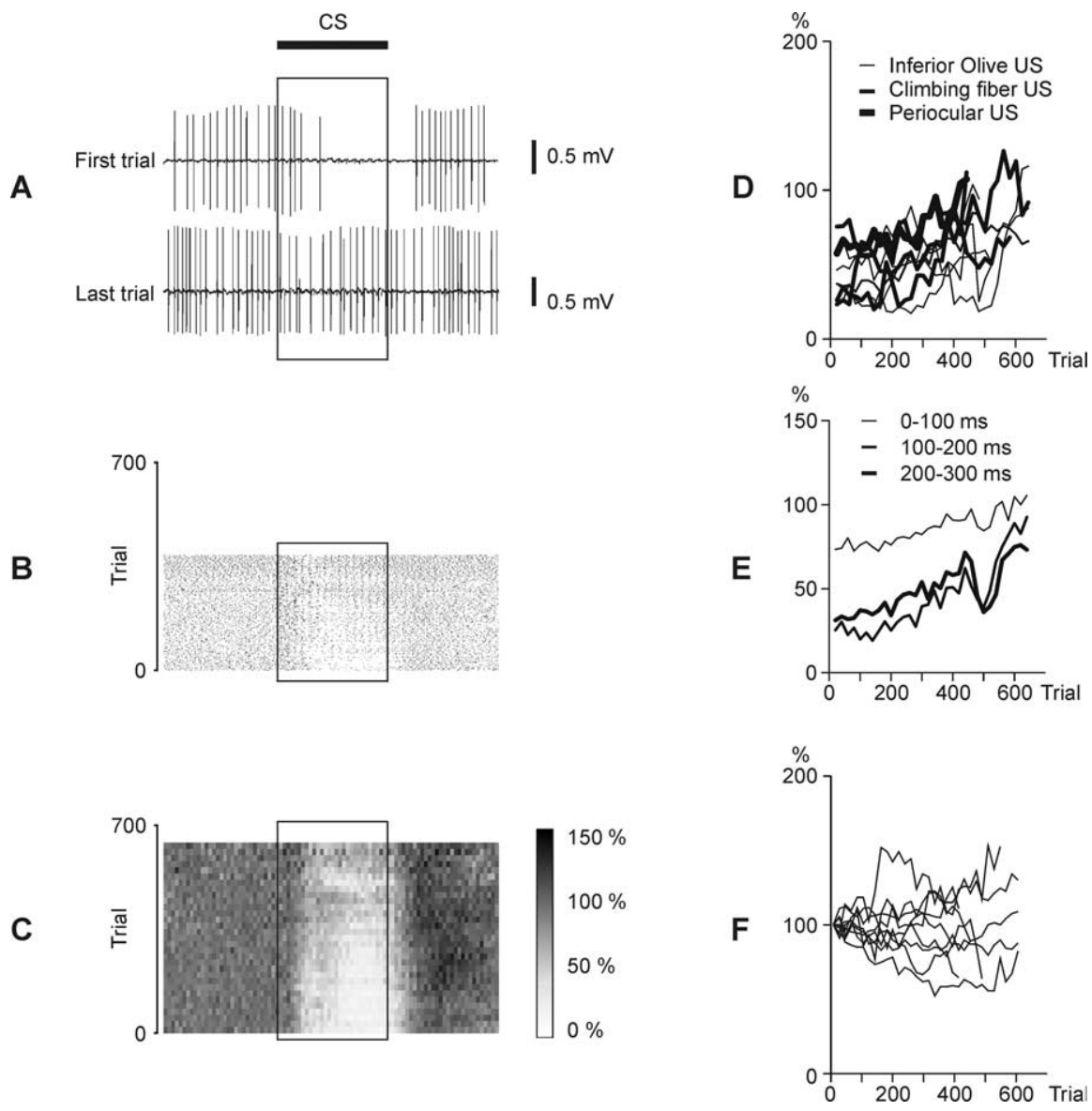

Figure 5. Purkinje cell activity during extinction. $A$, Two example records from a Purkinje cell exposed to unpaired CS-US stimulation (bar above graph indicates the $300 \mathrm{~ms}$ (S period), from trial 1 (top) and 440 trials later (bottom). The Purkinje cell CR had an onset latency of $60 \mathrm{~ms}$ and a duration of $300 \mathrm{~ms}$. $\boldsymbol{B}$, Raster plot of simple spike activity recorded from the same cell as above during 440 trials of unpaired CS-US stimulation. The inhibitory response during the CS period (framed) gradually extinguished as training progressed. C, Average raster plot of simple spikes recorded from nine Purkinje cells during paired CS-US stimulation. The plot is built of squares, the shadings of which indicate average firing rate across all cells (for details, see Materials and Methods). The light area that gradually disappears represents the Purkinje cell $C R$, i.e., an inhibitory response with firing rate below background level (100\%). D, Simple spike activity in nine individual Purkinje cells shown as plots of firing frequency (percentage of background activity) during the whole $300 \mathrm{~ms}$ (S period. There is a consistent increase of simple spike activity in all cells. $\boldsymbol{E}_{\text {, }}$ Temporal analysis of training induced changes of simple spike activity. The $300 \mathrm{~ms} C S$ period was divided into three $100 \mathrm{~ms}$ periods and plotted separately. $\boldsymbol{F}$, Spontaneous simple spike activity during the $600 \mathrm{~ms}$ period before $\mathrm{CS}$ presentation in nine individual Purkinje cell records, shown as percentage of background activity when recording started.

a small proportion of Purkinje cells in eyeblink controlling parts of the C3 zone exhibit pause responses to the CS in conditioned animals (Hesslow and Ivarsson, 1994). Others have also reported inhibitory responses, but most observed Purkinje cells have been either excited or nonresponsive (Berthier and Moore, 1986; Kotani et al., 2003, 2006; Green and Steinmetz, 2005). Furthermore, most of the previously reported recordings were made after training, leaving open the possibility that the observed firing patterns were not a result of learning.

In contrast, the data presented here are in perfect agreement with all cerebellar conditioning models that predict learning of Purkinje cell pauses in the cortex. They show for the first time a highly consistent and quite uniform change in the Purkinje cell response to the CS, from no effect or weak excitation before training to a strong and long-lasting inhibitory response after training. This Purkinje cell CR was observed in all 23 cells that met the sampling criteria. Furthermore, this is the first demonstration that a conditioned Purkinje cell response undergoes extinction during unpaired CS-US presentations and that reacqui- sition with substantial savings occurs when paired stimulation is reinstated.

The discrepant findings in the literature of nonresponsive Purkinje cells or increased responsiveness can very likely be explained by failures to identify the relevant Purkinje cells and/or to ascertain that they receive the critical CS and US inputs. It is also possible that there are functional differences between different cerebellar zones. Our recordings were strictly in C3, whereas most other studies have not identified the zones. Our previous finding that $<20 \%$ of the Purkinje cells in C3 showed inhibitory responses to the CS (Hesslow and Ivarsson, 1994) could have been attributable to slow learning because of weak climbing fiber activation elicited by the peripheral US, which was a periocular electrical skin stimulus. The inferior olive normally responds to peripheral input with a burst response with one to six spikes (Simpson et al., 1996). When a peripheral stimulus is used, we have no control over the number of the impulses in the olivary discharge, and this may be a critical factor in acquisition.

\section{Climbing and mossy fibers mediate CS and US signals}

The Purkinje cells acquired a CR whether the CS was a peripheral skin stimulus or direct mossy fiber stimulation, in agreement with previous demonstrations that mossy fiber stimulation can serve as a CS (Steinmetz et al., 1986) and that mossy fiber stimulation can elicit a previously acquired eyeblink response to a peripheral CS (Hesslow et al., 1999).

Acquisition of Purkinje cell CRs also occurred with three different ways of activating the climbing fibers. In most cases, the olivary stimulus was used as the US. Although only one cell (cell 13) was followed during acquisition training with a periorbital US, the extinction data from that cell together with extinction and reacquisition data from another cell (cell 14) provided evidence of Purkinje cell CRs after paired CS-US presentations with a peripheral US. Similarly, only one cell (cell 10) was followed during acquisition training with a climbing fiber US, but extinction and reacquisition data from another two cells (cells 11 and 12) provided evidence of Purkinje cell CRs after paired CS-US presentations with a climbing fiber US. Finally, reacquisition training using a climbing fiber US after acquisition to a periorbital US caused Purkinje cell CRs to reappear (in cell 14). Together, these observations strongly suggest that climbing fibers mediate the US.

This conclusion is also supported by previous findings that olivary stimulation can serve as a US (Mauk et al., 1986) and that nucleo-olivary signals influence learning (Medina et al., 2002; Bengtsson, 2005). The conclusion also fits with previous observations of CS elicited pauses in Purkinje cells in conditioned animals (Hesslow and Ivarsson, 1994). 
It is possible that direct olivary and climbing fiber stimulation produces more rapid learning in the Purkinje cell than a peripheral US, although the present data do not demonstrate this. Direct climbing fiber stimulation, especially when directed at fibers in the inferior cerebellar peduncle, circumvents the negative feedback inhibition of the olive provided by the nucleo-olivary pathway (Hesslow, 1986; Bengtsson and Hesslow, 2006; Svensson et al., 2006). Under normal circumstances, the response that develops in the interpositus nucleus during conditioning (Berthier and Moore, 1990) will inhibit the olive and reduce the efficacy of the US (Hesslow and Ivarsson, 1996) as training progresses. With direct climbing fiber stimulation, this feedback mechanism is short-circuited. This mechanism may also have contributed to less efficient learning in many of the Purkinje cells in our previous investigation (Hesslow and Ivarsson, 1994). However, acquisition of Purkinje cell CRs did not depend on using direct stimulation of the inferior olive or of the climbing fibers in the inferior cerebellar peduncle, because peripheral USs induced both initial learning and rapid reacquisition in the present study, consistent with our previous investigation.

\section{The Purkinje cell CR can explain the behavior}

The Purkinje cell CR cannot merely be a reflection of the behavior. The animals were curarized, so behavioral (i.e., sensory) feedback from the periorbital area could not have caused the Purkinje cell response. Second, the suppression of simple spike firing starts earlier than the overt behavior observed in similarly trained but noncurarized animals in previous investigations (Svensson et al., 1997; Hesslow et al., 1999), in some cases after just a couple of milliseconds, which is so short that it could not even reflect feedback from premotor signals. Third, the response was elicited by direct mossy fiber stimulation, which excludes all extracerebellar sources of input, including premotor structures.

The direction of causality must therefore be from Purkinje cell to behavior. Indeed, the Purkinje cell CR seems to have the properties necessary to explain most features of the behavioral CR. Purkinje cells inhibit the interpositus nucleus, and a pause in Purkinje cell firing would be expected to cause disinhibition in the nucleus. Because the nuclear neurons are spontaneously active (Thach, 1968; Raman et al., 2000), the Purkinje cell CR would be expected to generate an excitatory nuclear response, which in turn can elicit a blink. The demonstrations that the Purkinje cell CR extinguishes with unpaired CS-US presentations and that it reappears very fast when paired stimulation is reinstated after extinction also suggest that this how the conditioned blink is actually generated.
Another striking parallel between the Purkinje cell CRs and behavioral CRs that reinforces the above conclusion concerns adaptive timing. The latency to the peak of a behavioral CR tends to coincide with the US and thus be equal to the CS-US interval. The onset latencies also increase with increasing CS-US intervals but vary much less (Kehoe and Macrae, 2002). Similarly, when the animals in the present study were trained to a CS-US interval of $200 \mathrm{~ms}$ rather than $300 \mathrm{~ms}$, the latency to peak of the Purkinje cell CR was shorter. The onset latencies were also shorter but less so, again in agreement with behavioral observations.

Although the data are very suggestive, some limitations should also be pointed out. We know from previous work in several laboratories that the stimulation used in the present experiments results in overt conditioning (Hesslow and Yeo, 2002; Christian and Thompson, 2003), but, because our animals were curarized, we cannot say at which point during training overt CRs would have appeared. We do not know, therefore, how strong the 
simple spike suppression during the Purkinje cell CR needs to be to generate overt CRs, nor can we say whether the Purkinje cell CRs are sufficient or whether plasticity at sites downstream of the Purkinje cells is also necessary.

\section{Mechanisms behind Purkinje cell CRs}

The data suggest a cortical memory locus but do not permit us to conclude what the synaptic mechanism underlying the inhibitory Purkinje cell CR is. There are several possible sites of synaptic plasticity: parallel fibers onto Purkinje cells or inhibitory interneurons, interneurons onto Purkinje cells, or mossy fibers onto granule cells. It needs to be stressed, however, that there is a unique convergence of sensory input from parallel fibers onto Purkinje cells: hundreds of thousands of parallel fibers to a single Purkinje cell in small mammals (Napper, 1988). This is a highly desirable feature in a system suited for associative learning and one that makes the parallel fiber synapses onto the Purkinje cell a plausible site for such learning on theoretical grounds alone.

As mentioned above, these results do not rule out plasticity in the cerebellar nuclei, nor are they in conflict with observations that a learned blink response can occur without the cerebellar cortex as reported by several investigators (Mauk, 1997; Christian and Thompson, 2003). However, if conditioned responses are observed after cortical lesions or inactivations, they are always abnormal (Attwell et al., 2002; Hesslow and Yeo, 2002). In contrast, pharmacological blockade of mossy fiber input to the nuclei in two studies did not abolish normal, adaptively timed, blink CRs (Attwell et al., 2002; Aksenov et al., 2005).

Some groups have reported short-latency conditioned blink responses after cortical inactivations (Perrett et al., 1993; Ohyama and Mauk, 2001; Bao et al., 2002; Koekkoek et al., 2003; Ohyama et al., 2006). Some of these responses appear to be of extracerebellar origin (Koekkoek et al., 2003), but those that do depend on the cerebellum may be learned by a different mechanism in the interpositus nucleus, perhaps strengthening of excitatory synapses, as reported recently (Pugh and Raman, 2006). Whatever the nature of the short-latency conditioned blinks turns out to be, their existence does not contradict our main finding here. Our results clearly demonstrate the existence of a memory trace within the cerebellar cortex, which is observable in the activity of the single Purkinje cell and potentially explains the generation of a normal, adaptively timed, blink CR.

\section{Single-cell memory trace versus population coding}

Several features of the processes of extinction and reacquisition have encouraged speculation that they can be attributed to network properties in the cerebellum. For instance, it has been suggested that extinction could be a result of a different population of Purkinje cells learning to suppress the CR (Robleto et al., 2004). The savings phenomenon in reacquisition has been ascribed to learning mechanisms with different time characteristics in the cortex and nuclei (Kehoe, 1988; Medina et al., 2001). Our results instead suggest purely cortical mechanisms for both extinction and reacquisition, involving the same Purkinje cells that are involved in acquisition.

Population coding (learning distributed over many Purkinje cells) or interactions between different parts of the cerebellar network (involving, for example, nuclear cells) are not ruled out as memory mechanisms, but our data suggest that many of the basic behavioral phenomena in eyeblink conditioning can be explained at the level of the single Purkinje cell.

\section{References}

Aksenov DP, Serdyukova NA, Bloedel JR, Bracha V (2005) Glutamate neurotransmission in the cerebellar interposed nuclei: Involvement in classically conditioned eyeblinks and neuronal activity. J Neurophysiol 93:44-52.

Albus J (1971) A theory of cerebellar function. Math Biosci 10:25-61.

Attwell PJE, Ivarsson M, Millar L, Yeo CH (2002) Cerebellar mechanisms in eyeblink conditioning. Ann NY Acad Sci 978:79-92.

Bao SW, Chen L, Kim JJ, Thompson RF (2002) Cerebellar cortical inhibition and classical eyeblink conditioning. Proc Natl Acad Sci USA 99:1592-1597.

Bengtsson F (2005) The cerebello-olivary feedback system. PhD Thesis, Lund University.

Bengtsson F, Hesslow G (2006) Cerebellar control of the inferior olive. Cerebellum 5:7-14.

Berthier NE, Moore JW (1986) Cerebellar Purkinje cell activity related to the classically conditioned nictitating membrane response. Exp Brain Res 63:341-350.

Berthier NE, Moore JW (1990) Activity of deep cerebellar nuclear cells during classical conditioning of nictitating membrane extension in rabbits. Exp Brain Res 83:44-54.

Christian KM, Thompson RF (2003) Neural substrates of eyeblink conditioning: acquisition and retention. Learn Mem 10:427-455.

Christian KM, Thompson RF (2005) Long-term storage of an associative memory trace in the cerebellum. Behav Neurosci 119:526-537.

Ekerot CF, Gustavsson P, Oscarsson O, Schouenborg J (1987) Climbing fibres projecting to cat cerebellar anterior lobe activated by cutaneous A and C fibres. J Physiol (Lond) 386:529-538.

Gilbert PF, Thach WT (1977) Purkinje cell activity during motor learning. Brain Res 128:309-328.

Green JT, Steinmetz JE (2005) Purkinje cell activity in the cerebellar anterior lobe after rabbit eyeblink conditioning. Learn Mem 12:260-269.

Hesslow G (1986) Inhibition of inferior olivary transmission by mesencephalic stimulation in the cat. Neurosci Lett 63:76-80.

Hesslow G (1994a) Correspondence between climbing fibre input and motor output in eyeblink-related areas in cat cerebellar cortex. J Physiol (Lond) 476:229-244.

Hesslow G (1994b) Inhibition of classically conditioned eyeblink responses by stimulation of the cerebellar cortex in the decerebrate cat. J Physiol (Lond) 476:245-256.

Hesslow G, Ivarsson M (1994) Suppression of cerebellar Purkinje cells during conditioned responses in ferrets. NeuroReport 5:649-652.

Hesslow G, Ivarsson M (1996) Inhibition of the inferior olive during conditioned responses in the decerebrate ferret. Exp Brain Res 110:36-46.

Hesslow G, Yeo CH (2002) The functional anatomy of skeletal conditioning. In: A neuroscientist's guide to classical conditioning (Moore JW, ed), pp 86-146. New York: Springer.

Hesslow G, Svensson P, Ivarsson M (1999) Learned movements elicited by direct stimulation of cerebellar mossy fiber afferents. Neuron 24:179-185.

Ito M (2001) Cerebellar long-term depression: characterization, signal transduction, and functional roles. Physiol Rev 81:1143-1195.

Ivarsson M, Hesslow G (1993) Bilateral control of the orbicularis oculi muscle by one cerebellar hemisphere in the ferret. NeuroReport 4:1127-1130.

Kehoe EJ (1988) A layered network model of associative learning: learning to learn and configuration. Psychol Rev 95:411-433.

Kehoe EJ, Macrae M (2002) Fundamental behavioral methods and findings in classical conditioning. In: A neuroscientist's guide to classical conditioning (Moore JW, ed), pp 171-231. New York: Springer.

Koekkoek SKE, Hulscher HC, Dortland BR, Hensbroek RA, Elgersma Y, Ruigrok TJH, De Zeeuw CI (2003) Cerebellar LTD and learningdependent timing of conditioned eyelid responses. Science 301:1736-1739.

Kotani S, Kawahara S, Kirino Y (2003) Purkinje cell activity during learning a new timing in classical eyeblink conditioning. Brain Res 994:193-202.

Kotani S, Kawahara S, Kirino Y (2006) Purkinje cell activity during classical eyeblink conditioning in decerebrate guinea pigs. Brain Res 1068:70-81.

Lavond DG (2002) Role of the nuclei in eyeblink conditioning. Ann NY Acad Sci 978:93-105.

Marr D (1969) A theory of cerebellar cortex. J Physiol (Lond) 202:437-470.

Mauk MD (1997) Roles of cerebellar cortex and nuclei in motor learning: contradictions or clues? Neuron 18:343-346. 
Mauk MD, Donegan NH (1997) A model of Pavlovian eyelid conditioning based on the synaptic organization of the cerebellum. Learn Mem 4:130-158.

Mauk MD, Steinmetz JE, Thompson RF (1986) Classical conditioning using stimulation of the inferior olive as the unconditioned stimulus. Proc Natl Acad Sci USA 83:5349-5353.

McCormick DA, Thompson RF (1984) Cerebellum: essential involvement in the classically conditioned eyelid response. Science 223:296-299.

Medina JF, Garcia KS, Mauk MD (2001) A mechanism for savings in the cerebellum. J Neurosci 21:4081-4089.

Medina JF, Nores WL, Mauk MD (2002) Inhibition of climbing fibres is a signal for the extinction of conditioned eyelid responses. Nature 416:330-333.

Napper RMHRJ (1988) Number of parallel fiber synapses on an individual Purkinje cell in the cerebellum of the rat. J Comp Neurol 274:168-177.

Ohyama T, Mauk MD (2001) Latent acquisition of timed responses in cerebellar cortex. J Neurosci 21:682-690.

Ohyama T, Nores WL, Medina JF, Riusech FA, Mauk MD (2006) Learninginduced plasticity in deep cerebellar nucleus. J Neurosci 26:12656-12663.

Perrett SP, Ruiz BP, Mauk MD (1993) Cerebellar cortex lesions disrupt learning-dependent timing of conditioned eyelid responses. J Neurosci 13:1708-1718.

Pugh JR, Raman IM (2006) Potentiation of mossy fiber EPSCs in the cerebellar nuclei by NMDA receptor activation followed by postinhibitory rebound current. Neuron 51:113-123.

Raman IM, Gustafson AE, Padgett D (2000) Ionic currents and spontane- ous firing in neurons isolated from the cerebellar nuclei. J Neurosci 20:9004-9016.

Robleto K, Poulos AM, Thompson RF (2004) Brain mechanisms of extinction of the classically conditioned eyeblink response. Learn Mem 11:517-524.

Schmahmann JD (1997) The cerebellum and cognition. New York: Academic.

Simpson JI, Wylie DR, De Zeeuw CI (1996) On climbing fiber signals and their consequences. Behav Brain Sci 19:384-398.

Steinmetz JE, Rosen DJ, Chapman PF, Lavond DG, Thompson RF (1986) Classical conditioning of the rabbit eyelid response with a mossy-fiber stimulation CS. I. Pontine nuclei and middle cerebellar peduncle stimulation. Behav Neurosci 100:878-887.

Svensson P, Ivarsson M, Hesslow G (1997) Effect of varying the intensity and train frequency of forelimb and cerebellar mossy fiber conditioned stimuli on the latency of conditioned eye-blink responses in decerebrate ferrets. Learn Mem 4:105-115.

Svensson P, Bengtsson F, Hesslow G (2006) Cerebellar inhibition of inferior olivary transmission in the decerebrate ferret. Exp Brain Res 168:241-253.

Thach WT (1968) Discharge of Purkinje and cerebellar nuclear neurons during rapidly alternating arm movements in the monkey. J Neurophysiol 31:785-797.

Thompson RE (2005) In search of memory traces. Annu Rev Psychol 56:1-23.

Yeo CH, Hardiman MJ, Glickstein M (1985) Classical conditioning of the nictitating membrane response of the rabbit. III. Connections of cerebellar lobule HVI. Exp Brain Res 60:114-126. 